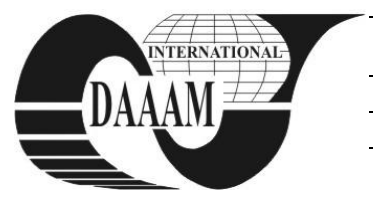

Annals of DAAAM for 2011 \& Proceedings of the 22nd International DAAAM Symposium, Volume 22, No. 1, ISSN 1726-9679 ISBN 978-3-901509-83-4, Editor B. Katalinic, Published by DAAAM International, Vienna, Austria, EU, 2011 Make Harmony between Technology and Nature, and Your Mind will Fly Free as a Bird Annals \& Proceedings of DAAAM International 2011

\title{
FUNCTIONAL FINISHING OF FIBROUS SUBSTRATES COATED WITH AG- DEPOSITED TIO2 NANOPARTICLES
}

\author{
VRINCEANU, N[arcisa]; COMAN, D[iana]; POPOVICI, E[veline]; BRINZA, F[lorin] \& NICA, V[alentin]
}

\begin{abstract}
This research aimed at the development of nanostructural fibrous composites with optimal dispersion containing $\mathrm{Ag}$ deposited $\mathrm{TiO}_{2}$ nano-particles, providing enhanced barrier properties. Firstly, the study was focused on the synthesis of $\mathrm{Ag}$-deposited $\mathrm{TiO}_{2}$ particles formed by a chemical reduction method. the morphology and microstructure of Ag-deposited $\mathrm{TiO}_{2}$ particles have been determined. Secondly, the characterization of the nanoscale finished surfaces has been performed using a co-assisted system: surface area measurements (adsorption/desorption isotherms, surface area measurement and pore size distribution).The structural properties of these as-prepared nanocomposites were characterized with scanning electron microscopy (SEM) and Xray diffraction $(X R D)$, showing that Ag-deposited $\mathrm{TiO}_{2}$ nanoparticles were deposited on the surface of studied textile. Due to the uniformity distribution of $\mathrm{Ag}$ deposited $\mathrm{TiO}_{2}$ nanoparticles onto the surface of supports, our results could be considered a preliminary step towards a safe methodology of nano-particles incorporation into selected fibrous substrates with multifunctionality, such as: self-cleaning performance, $U V$ protection, photocatalyti, water stability etc.

Key words: fibrous substrates, nanotechnology, Ag-deposited $\mathrm{TiO}_{2}$, nanoparticles, functionalization, finishing fibrous substrates, nanotechnology, finishing
\end{abstract}

\section{INTRODUCTION}

Innovative materials, including textiles for specific applications, have to satisfy consumers' growing demands (Tsuji, 2002). It is extremely important, even compulsory that a material should perform several functions, due to various applications, wearing and also economic aspects.

There are some nanoparticles of metal-oxides: titanium $\left(\mathrm{TiO}_{2}\right)$ and zinc $(\mathrm{ZnO})$ belonging to a group of compounds with photo-catalytic properties, which are able to absorb UV radiation. There are researches involving metal deposition (Esumi,1998) and much attention has been paid to doping the material with transition and noble metals such as Pd, Pt (Esumi, 1998), Rh, Au, and Ag (Innocezi, 2000). In this work, silver nanoparticles were deposited on the surface of $\mathrm{TiO}_{2}$ particles by using a chemical reduction method (Shirai, 1999). In the formation process of silver nanoparticles by the chemical reduction method, there are several factors that influence in a great extent the preparing of nano-sized silver powder. Important parameters, such as the molar concentration ratio of $\mathrm{R}$ ([ $\left.\mathrm{AgNO}_{3}\right]$ [reducing agent]), the dispersant concentration, and the feed rate of reactant, affect the properties of the silver nanoparticles obtained by this method (Andrzejewska, 2004; Jesionowski, 2001). The main aim of these research works was the development of nano-scaled textile composites with barrier properties.

In the first stage, the works focused on:

- a method for the synthesis of $\mathrm{Ag}$ - deposited $\mathrm{TiO}_{2}$ nanoparticles by using a chemical reduction method;

- a methodology of nano-particles incorporation into selected fibrous substrates.

\section{EXPERIMENTAL}

Materials and methods. Nanoparticle preparation/Synthesis of Ag-deposited $\mathrm{TiO}_{2}$ nanoparticles. In all experiments the $\mathrm{TiO}_{2}$ nanoparticles used were synthesized. The ageing of $\mathrm{TiO}_{2}$ suspensions lasted for $30 \mathrm{~min}$ in an ultrasonic bath, to which were added the required quantities of silver nitrate $\left(\mathrm{AgNO}_{3}\right.$ (99.99\%), Aldrich) with SDS (sodium dodecyl sulfate $\left(\mathrm{CH}_{3}\left(\mathrm{CH}_{2}\right)_{11} \mathrm{OSO}_{3} \mathrm{Na}(99 \%)\right.$, Aldrich) such that the desired $\mathrm{Ag} / \mathrm{Ti}$ atomic concentration ratio was obtained. After mixing, Ag-deposited $\mathrm{TiO}_{2}$ suspensions were prepared by feeding in hydrazine hydrate $\left(\mathrm{N}_{2} \mathrm{H}_{4} \times \mathrm{H}_{2} \mathrm{O}(98 \%)\right.$, Aldrich) aqueous solution. In this experiment, hydrazine hydrate and sodium dodecyl sulfate played the role of reducing agent and dispersant, respectively.

\subsection{Nanoscaled finishing of linen fabrics with Ag-deposited $\mathrm{TiO}_{2}$ particles}

For the experimental purpose small fine-medium weight $100 \%$ linen woven fabrics were used. Linen fabrics were washed and dried, before being used. The dimensions of samples were of $4 \times 12 \mathrm{~cm}^{2}$. The application of Ag-deposited $\mathrm{TiO}_{2}$ particles on linen has been performed using pad-dry-cure method. For the successive treatment of fabrics with colloidal silver, the solution was agitated continuously. The linen samples were immersed in the solution $(150 \mathrm{~mL})$ containing Ag-deposited $\mathrm{TiO}_{2}$ particles, for $5 \mathrm{~min}$, then squeezed to $100 \%$ wet pick up with laboratory padder at constant pressure. A subsequently immersion for $5 \mathrm{~min}$ in $2 \mathrm{~g} / \mathrm{L}$ of sodium lauryl sulfate has been performed to remove unbound nanoparticles. To completely take out all the soap solution, the fabric was rinsed at least 10 times. The drying took place at $70{ }^{\circ} \mathrm{C}$ for 3 $\mathrm{min}$, followed by curing at $150^{\circ} \mathrm{C}$ for $2 \mathrm{~min}$.

\subsection{Characterization of Ag-deposited $\mathrm{TiO}_{2}$ nanoparticles}

SEM photographs were used to observe the distribution of silver deposited on the $\mathrm{TiO}_{2}$ surface. As shown in Fig. 1, a small amount of silver particles with a size of $5 \mathrm{~nm}$ was deposited on the surface of the $\mathrm{TiO}_{2}$ particles. It can be confirmed that silver particles were deposited on the surface of the individual $\mathrm{TiO}_{2}$ crystallites.
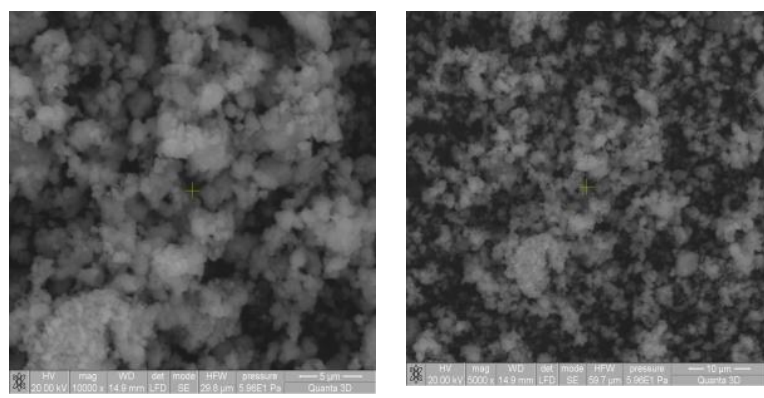

Fig.1. SEM image of Ag-deposited $\mathrm{TiO}_{2}$ nanoparticles 


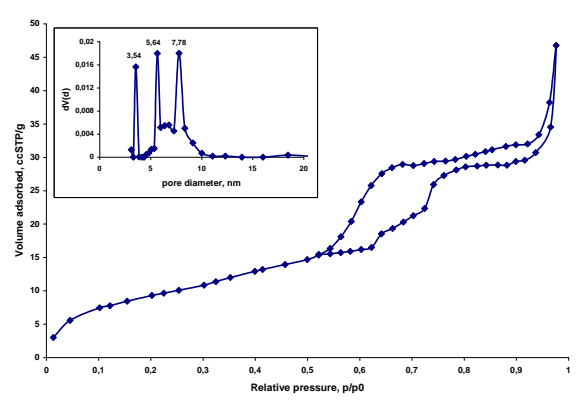

Fig. 2. Nitrogen adsorption-desorption isotherms (inset) and pore size distribution plots for linen sample treated with Agdeposited $\mathrm{TiO}_{2}$ particles

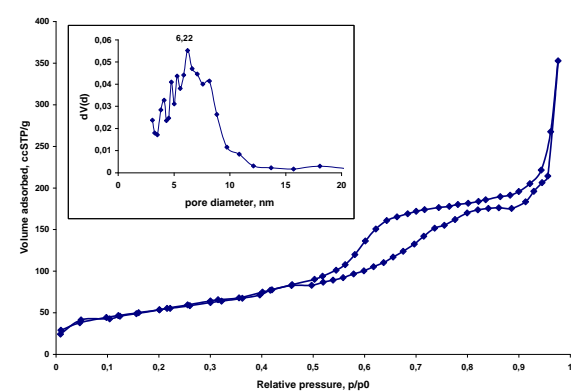

Fig. 3. Nitrogen adsorption-desorption isotherms (inset) and pore size distribution plots for Ag-deposited $\mathrm{TiO}_{2}$ particles

The particle size and the size distribution of Ag-deposited $\mathrm{TiO}_{2}$ nanoparticles were observed using a Nova High Speed Gas Sorption Analyser. Both reference and tested samples show a type-IV isotherm, which is representative of mesoporous solids (Fig 2 and Fig. 3). The specific surface area of the $\mathrm{Ag} / \mathrm{TiO}_{2}$ composite is $176 \mathrm{~m}^{2} / \mathrm{g}$, by means of Brunauer Emmett - Teller (BET) method. The pore diameter of the $\mathrm{Ag} / \mathrm{TiO}_{2}$ is $6.22 \mathrm{~nm}$ (estimated using the desorption branch of the isotherm) with very narrow pore size distribution.

The $\mathrm{TiO}_{2}$ possesses virtually identical average pore diameter $(5 \mathrm{~nm})$ and specific surface area $\left(189 \mathrm{~m}^{2} / \mathrm{g}\right)$, considering a typical uncertainty of $5 \%$ for BET surface area measurements. The addition of $\mathrm{Ag}$ causes a slight decrease, from 0.261 to $0.007 \mathrm{~cm}^{3} / \mathrm{g}$, in the pore volume of $\mathrm{TiO}_{2}$.

Fig. 4 shows the X-ray diffraction patterns of Ag-deposited $\mathrm{TiO}_{2}$ powders $\mathrm{TiO}_{2} / \mathrm{AgNO}_{3}$ for $2 \theta$ diffraction angles between $5^{\circ}$ and $70^{\circ}$. The XRD pattern of $\mathrm{TiO} 2$ shows five primary peaks at: $25,4^{\circ}, 38,1^{\circ}, 48,14^{\circ}, 54,7^{\circ}$ and $63,04^{\circ}$, which can be assigned to different diffraction planes of anatase $\mathrm{TiO} 2$.

As shown in Fig. 4, the most intense (101) peak was observed at $29=25.34^{\circ}$, meaning the interference-free reflection of the typical tetragonal anatase structure. Results reveal that the addition of silver did not significantly affect the crystal size. The XRD patterns of silver deposited $\mathrm{TiO} 2$ samples almost coincide with that of pure $\mathrm{TiO} 2$ showing no diffraction peaks due to silver deposition thus suggesting that the silver are merely placed on the surface of the crystals.

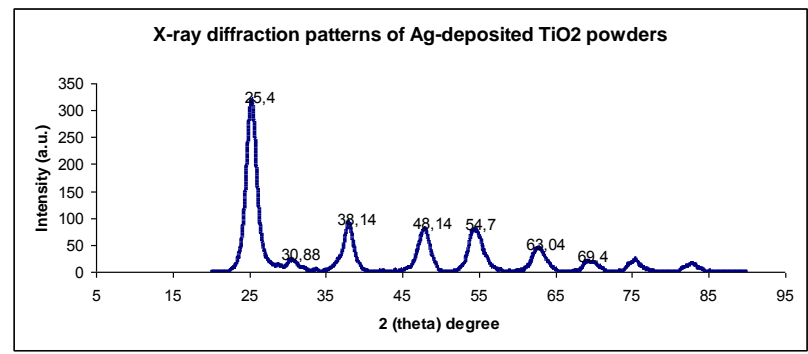

Fig. 4. X-ray diffraction patterns of $\mathrm{Ag}$-deposited $\mathrm{TiO}_{2}$ powders

\begin{tabular}{|c|c|c|c|}
\hline Sample & $\mathrm{S}, \mathrm{m}^{2} / \mathrm{g}$ & $\mathrm{Vp}, \mathrm{cc} / \mathrm{g}$ & Pore diameter, $\mathrm{nm}$ \\
\hline $\mathrm{TiO}_{2}$ & 189 & 0.423 & 5 \\
\hline $\mathrm{TiO}_{2} / \mathrm{Ag}$ & 176.301 & 0.261 & 6.22 \\
\hline Linen $+\mathrm{TiO}_{2} / \mathrm{Ag}$ & 31.542 & 0.007 & 7.78 \\
\hline
\end{tabular}

Tab. 1. Textural properties

These results show that the deposition of Ag particles does not significantly change the textural properties of $\mathrm{TiO}_{2}$, properly due to the small amount of Ag loaded. Thus, most of the pore channels in $\mathrm{TiO}_{2}$ film are open, although a small portion of the channels may be filled with the Ag particles. Such open mesoporous architecture with large surface area and $3 \mathrm{D}$ connected pore-system is an important consideration in catalyst design because it can improve the molecular transport of reactants and products.

These results are the consequence of the presence of $\mathrm{Ag}$ particles and their interaction with $\mathrm{TiO}_{2}$ particles. Summarizing, the high dispersion of silver nanoparticles is thoroughly achieved by encapsulation in the pore channels of ordered mesoporous $\mathrm{TiO}_{2}$ film. The Ag particles are well confined in the pore channels and the particle size can be controlled to below $5 \mathrm{~nm}$. Such porous architecture and dimensions are desirable features for catalytic and photocatalytic applications.

\section{CONCLUSION AND PERSPECTIVES}

This study revealed the silver deposited $\mathrm{TiO}_{2}$ nanoparticles synthesis by a chemical reduction method and the nanoscaled finishing with $\mathrm{Ag}$-deposited $\mathrm{TiO}_{2}$ powders onto fabrics. The main aim of these research works was the development of appropriate nano-structural textile composites with barrier properties. The research had two phases: (1) a methodology for the synthesis of $\mathrm{Ag}$ - deposited $\mathrm{TiO}_{2}$ nanoparticles by using a chemical reduction method and (2) the methodology of nanoparticles incorporation into selected fibrous substrates.

The characterization of Ag-deposited $\mathrm{TiO}_{2}$ nanoparticles suggested that such porous architecture and dimensions are desirable features for providing a high multifunctionality: photocatalytic applications, photoprotective, self-cleaning of nano-structural textile composites.

Our future research will be focused towards potential barrier properties of this type of nano-scaled textile composites obtained, as well as their photocatalytic activity.

\section{ACKNOWLEDGEMENTS}

This work was supported by the Research Contract within POSDRU No. /89/1.5/S/49944 Project.

\section{REFERENCES}

Andrzejewska, A., Krysztafkiewicz, A., Jesionowski, T. (2004), Dyes Pigments, 62(2), p. 121-130

Esumi, K., Hayashi, H., Koide, Y., Suhara, T., Fukui, H. (1998). Colloids Surf. A., 144, p. 201

Esumi, K., Sakai, K., Torigoe, K., Suhara, T., Fukui, H. (1999), Colloids Surf. A., 155, p. 413

Innocezi, P., Brusatin, G., Guglielmi, M., Sognorini, R., Bozio, R., Moggini M. (2000). J. Non-Crystalline Solids, 265, p. 68

Jesionowski, T., (2001). Pigment Resin Technol., 30, p. $287-$ 295

Jesionowski T., Krysztafkiewicz A., Dec A. (2001). Physicochemical Problems of Mineral Processing, 35, p. 195-205Tsuji, H., Sagimori T., Kurita, K., Gotom, Y.,

Ishikawa, J. (2002). Surf. Coat. Technol., 158-159, , p. 208-213

Shirai Y., Kawatsura K. and Tsubokawa N. (1999). Progress in Organic Coatings, 36, p. 217 